\title{
OBTAINMENT OF WUCHERERIA BANCROFTIINFECTIVE LARVAE (L3) FROM CULEX QUINQUEFASCIATUS (DIPTERA: CULICIDAE) USING AN ARTIFICIAL FEEDING TECHNIQUE
}

\section{CLEIDE M. R. ALBUQUERQUE; JANAINA C. M. NEVES* \& ROBERTO P. WERKHÄUSER*}

\author{
Departamento de Zoologia, UFPE, Recife, PE, Brasil *Centro de Pesquisas Aggeu Magalhães - FIOCRUZ, \\ Caixa Postal 7471, 52020-020 Recife, PE, Brasil
}

In greater Recife, northeast Brazil, Culex quinquefasciatus has been considered to be the only vector of Wuchereria bancrofti, a nematode parasite of man that is responsible for the most important lymphatic filariasis. This disease has been recognized as endemic since the fifties and it has been causing serious problems of public health (R. G. Rachou, 1956, Rev. Bras. Malariol. D. Trop., 8: 267-279; G. Dreyer \& Z. Medeiros, 1990, Ciên. Hoje, 12: 6-7).

Production of infective larvae (L3) enough to perform essential studies of the immunology and biochemistry of $W$. bancrofti, is usually obtained through the xenodiagnosis method.

This consists of infecting the mosquitoes by feeding them on carriers of microfilariae. However, this method presents the major limitations of having to submit the volunteers to a 2 hour-bite period, at night.

We have succeeded in obtaining L3 from infected insects using an artificial feeding technique. The membrane feeding apparatus used was slightly modified from those of $\mathrm{L}$. C. Rutledge et al. (1964, Mosq. News, 24: 407419) and P. S. Mellor, (1971, Trans. R. Soc. Trop. Med. Hyg., 2: 199-201). These modifications have enabled us, both to use small blood samples (around $3.0 \mathrm{ml}$ ) and to keep the cells in suspension during the feeding procedure.

Supported by: FIOCRUZ/UDNP/WORLD BANK/WHO (TDR).

Received 10 April 1992.

Accepted 30 September 1992.
Four different kinds of membrane were tested for their performance in feeding $C$. quinquefasciatus. Two of them were animal membranes (mouse peritoneum and chicken crop) and the others were synthetic (parafilm " $M$ " and condom without lubricant). Although, in general, animal membranes are believed to be superior to those of synthetic origin (L. C. Rutledge et al., 1964, Mosq. News, 24: 407419; T. Ponnudurai et al., 1971, J. Helmintol., $X L V$ : 415-418; P. S. Mellor, 1971, Trans. R. Soc. Trop. Med. and Hyg., 65: 199-201), this belief was not supported by our experiments. Best results occurred when condoms were used. On this synthetic membrane, the mosquitoes fed three times more than when placed on animal membranes. Moreover, the condom is easily available. Therefore, this kind of membrane was chosen for all subsequent feeding trials.

Adult specimens of $C$. quinquefasciatus were maintained at room temperature on a $10 \%$ glucose diet and usually starved $20-24 \mathrm{~h}$ before the blood meal. Insects used in these experiments were obtained from egg rafts. Collection was made in two different suburbs of greater Recife. Experimental feeding was carried out using seven day old females which were allowed to feed for $4 \mathrm{hr}$ on infected blood in a dark room. Human venous blood $(5.0 \mathrm{ml})$ was drawn at 11:00 p.m. and coagulation was prevented by adding of $0.1 \mathrm{ml}$ of $1 \%$ EDTA solution per $\mathrm{ml}$ of blood. The microfilaremia levels were determined by a nucleopore membrane filtration technique, ranging from 900 up to $3,583 \mathrm{microfilariae}$ per $\mathrm{ml}(\mathrm{mf} / \mathrm{ml})$. Phagostimulants were not used in these experiments.

In the first series of experiments the mosquitoes which consumed blood were dissected 
TABLE

Number of Wuchereria bancrofti infective larvae (L3s) in Culex quinquefasciatus, 23 days after artificial membrane feeding on blood with different $\mathrm{mf}$ densities

\begin{tabular}{cccccc}
\hline $\begin{array}{c}\text { Exper. } \\
\text { number }\end{array}$ & $\mathrm{mf} / \mathrm{ml}$ & $\begin{array}{c}\text { Engor. } \\
\text { mosq. }\end{array}$ & $\begin{array}{c}\text { No. of } \\
\text { infective } \\
\text { mosq. }(\%)\end{array}$ & $\begin{array}{c}\text { Mean no. of } \\
\text { L3/mosq. }\end{array}$ & $\begin{array}{c}\text { Mean no. of } \\
\text { L3/infective } \\
\text { mosquito }\end{array}$ \\
\hline 1 & 900 & 29 & $05(17)$ & 0.2 & 1.0 \\
2 & 1,300 & 17 & $05(29)$ & 0.3 & - \\
3 & 1,650 & 22 & $04(18)$ & 0.3 & 1.0 \\
4 & 1,800 & 22 & $11(28)$ & 0.4 & 1.4 \\
5 & 2,983 & 38 & $03(09)$ & 0.1 & 1.0 \\
\hline
\end{tabular}

Exper. $=$ experiment $; \mathrm{mf}=$ mictofilariae $;$ mosq. $=$ mosquito $(\mathrm{es}) ;$ Engor. $=$ engorged.

after 23 days and examined for filarial infection. That was the period, which has been normally applied in the insectary of the Centro de Pesquisas Aggeu Magalhães, with a room temperature of around $24^{\circ} \mathrm{C}$ and a room humidity of about $50 \%$. No clear relationship among $\mathrm{mf}$ density, percentage of infective mosquitoes and number of L3 per infective mosquito was observed (Table).

Since the two chosen areas for collection of egg rafts were around $7 \mathrm{~km}$ apart from each other, it is possible speculate about the existence of different mosquito strains.

This distance could be a geographic barrier because $C$. quinquefasciatus has a small amplitude movement (some meters) in an urban environment (R. Subra, 1972, Cah. O.R.S.T. O. M. sér. Ent. méd. et Parasitol., X: 3-36).

In such a case, we might suppose distinct infection susceptibilities to the microfilariae of $W$. bancrofti to explain the above mentioned findings. The use of a small number of mosquitoes (nearly 100) per sample is another likely explanation for these results.

In another experiment, 198 insects were engorged on infected blood $(3,333 \mathrm{mf} / \mathrm{ml})$. In order to determine the amount of microfilariae ingested per insect, 36 of the engorged mosquitoes were dissected up to $24 \mathrm{hr}$ after feeding. From this group, $17(47.2 \%)$ specimens were found to be infected and the average number of microfilariae per mosquito was 0.86 . The number of $\mathrm{mf}$ taken up by each infected mosquito ranged from 1 to 6 (average number of $1.82 \mathrm{mf}$ per infected mosquito). The remaining 162 engorged mosquitoes were maintained for 15 days, in the same conditions as the prior experiment, except for temperature and humidity $\left(28{ }^{\circ} \mathrm{C}\right.$ and $70 \%$ respectively). This group was used in the studies related to filarial development and mortality rates. Dead mosquitoes were counted and removed daily. After 15 days, the surviving mosquitoes (116) of this group were dissected and an average number of $0.42 \mathrm{~L} 3$ per mosquito was found. From these 116 insects, $29.3 \%$ became infective with an average number of $1.44 \mathrm{mf}$ per infected mosquito. All these data indicate that about $20.9 \%$ of the ingested microfilariae were not recovered after the 15 day period. This phenomenon might be explained by a failure in the complete L3 development or by an excessive charge of microfilariae in the insects that died over the waiting time referred to above.

On the other hand, we don't have data on the kinetic distribution of the microfilariae in the blood sample during feeding. The mortality rate analysis was obtaind by comparing the data collected after 15 days of infective blood meal $(28.4 \%)$ with a control group that was fed on non-infected blood $(9.0 \%)$. Therefore, the experimental group showed approximately a 3-fold higher death rate over a 15 day period than the control group. Apparently, the survival of the mosquitoes could have been affected by the $W$. bancrofti infection as suggested by other authors (W. J. Crans, 1973, J. Med. Ent., 10: 189-193). Additional experiments are currently being carried out in our laboratory to try to determine if the filaria developmental stage may have an influence on the mortality rate. All the infective larvae recovered were cryopreserved as described by $P$. J. Ham et al. (1981, Parasitology, 83: 139146). 
Despite the necessity to compare the membrane feeding technique and the xenodiagnosis method, the former approach should already be carefully considered as a new way for obtainment of $W$. bancrofti $\mathrm{L} 3$ and diagnosis purposes, using the local vector, $C$. quinquefasciatus.

This procedure might have the extra ad- vantage of avoiding the insects having to inflict bites upon the carriers during natural feeding.

Acknowledgement: to Dr Amélia Maciel and Dr Gerusa Dreyer for the infected blood support; to Dr Alexandre B. de Carvalho for reviewing the manuscript and Raimundo Pimentel for the technical aid. 